\title{
Quality of Coffea canephora beverage as a function of genotype, processing method and grain size
}

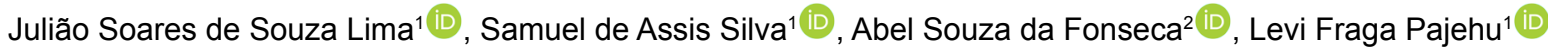

\author{
${ }^{1}$ Universidade Federal do Espírito Santo/UFES, Departamento de Engenharia Rural, Alegre, ES, Brasil \\ ${ }^{2}$ Escola Família Agrícola de Ibitirama, Ibitirama, ES, Brasil \\ Contact authors: limajss@yahoo.com.br, samuel.assilva@gmail.com, abelsouzafonseca@gmail.com, Ifp_bips@hotmail.com \\ Received in February 3, 2020 and approved in July 6, 2020
}

\section{ABSTRACT}

After harvesting, the coffee beans tend to lose quality during fruit processing and grain storage, thus affecting the quality of the obtained beverage. The objective of this research was to evaluate the quality of the beverage obtained from conilon coffee (Coffea canephora) for seminal (S) and clonal (C) genotypes, two processing methods of the coffee cherries (natural and peeled), different sizes of coffee beans determined by sieves and two storing periods of 45 and 90 days. The coffee cherries were dried, natural $(N)$ and peeled $(P)$, on cement floor in greenhouse and classified through the $13,14,15,16$ and 17 sieves. After 45 days of storage, it is observed that the overall score (OS) of the beverage prepared from peeled clonal (PC) and natural seminal (NS) coffee beans increased with increasing bean size (sieves 15 and 16). The treatments PS13, PS14, PS15, PS16, PC15 and PC16 were significantly different, however, the overall score (OS) decreased after samples were stored for 90 days. It is concluded that after storing the coffee bean samples for 45 and 90 days, the OS decreased significantly for peeled seminal coffee (PS) sieves 13, 14, 15, and 16 and peeled clonal coffee (PC) sieves 15 and 16

Key words: Coffee drink score; Cup quality; Sensory analysis.

\section{INTRODUCTION}

The quality of the beverage the conilon coffee beans (Coffea canephora) has been the object of several studies due to the demanding domestic and international markets. The market demand for the consumption better quality coffee is leading farmers to improve production processes in order to achieve higher results in the final global score of beverages in the hedonic scale (Fonseca et al., 2019). One of the methods for assess the quality of the beverage is a sensory analysis, which depends on the sensitivity and tasting experience of accredited tasters based on specific protocols.

The sanitary viability of coffee beans is an important factor for producing both seedlings and beans for industrialization, such as coffee beans for beverage. The period between the harvest ripe fruits and transport those to the drying place can promote the fermentation of the fruits due to the favorable conditions for the improvement biological processes, which may not only cause losses and damage to the beans, but also interfere in the quality of the beverage (Verdin Filho et al., 2016). Silva et al. (2020) studying fungi associated to beans infested with coffee berry borer and the risk of ochratoxin A complement the importance, mainly of Penicillium sp.

Several coffee cultivars with important productive and vegetative characteristics have been developed. Both the coffee genotype and the environment influence beverage quality (Souza et al., 2018). However, it is necessary to evaluate the microorganisms associated with the beans of different cultivars to ensure improving the quality of the coffee beverage (Pasin; Almeida; Abreu, 2009). Of the mycotoxins present in coffee beans, Ochratoxin A (OTA) is the most common and poses a great risk to the consumption and trade of the product (Pimenta; Vilela, 2003). Coffee beans without contamination depend on drying and storage as shown by Taveira et al. (2015), who comment that the drying procedures influence the physiological quality the beans also the quality of the beverage.

Lima and Silva (2018) evaluated the quality of the beverage the conilon coffee, clonal variety, and reported better results for coffee grown in higher altitude and depulped coffee cherry dried naturally while no fungi were detected after a 45day storage period.

The storage period of coffee samples even in hermetically sealed packaging, alters the quality of the coffee beverage due to fungal manifestation in the beans. In this context the objective of this research was to evaluate the quality of the beverage prepared from conilon coffee beans (Coffea canephora) of two genotypes (seminal and clonal), two processed cherry fruits [peeled $(\mathrm{P})$ and natural $(\mathrm{N})$ ] classified in the different sieves and two storing periods, 45 and 90 days.

\section{MATERIAL AND METHODS}

The experiment was carried out in two commercial crops of Conilon coffee (Coffea canephora Pierre) cultivated in 540.0 m average altitude, during the 2016/2017 and 2017/2018 harvests, and two genotypes: seminal (S) and clonal (C) seed propagation (Vitoria - INCAPER 8142). The coffee farm is located at 203' $31^{\prime \prime}$ S and $41^{\circ} 05^{\prime} 22^{\prime \prime} \mathrm{W}$, in the São Vicente District, Cachoeiro de Itapemirim, ES. The altitude in this hilly region, known as the seas of hills, exceeds 800 meters in some locations. 
According to Köppen and Geiger (1928), the climate classified as $\mathrm{Cwa}, \mathrm{Cwb}$, and $\mathrm{Aw}$ in the Cachoeiro de Itapemirim region, so that the Tropical Cwa is the prevailing climate in the region. In the 2016/2017 harvest, the maximum and minimum temperatures were $32.7{ }^{\circ} \mathrm{C}$ (December/16) and $14.7{ }^{\circ} \mathrm{C}$ (April/17), respectively, with $300 \mathrm{~mm}$ maximum monthly rainfall (December/16) and $1167 \mathrm{~mm}$ accumulated rainfall. In the $2017 / 2018$ harvest, the maximum temperature was $33.3{ }^{\circ} \mathrm{C}\left(\right.$ January/18) and the minimum, $14.0{ }^{\circ} \mathrm{C}$ (May/18), with $200.4 \mathrm{~mm}$ maximum rainfall (February/18) and $1198 \mathrm{~mm}$ accumulated rainfall.

In the 2016/2017 harvest, precipitation events greater than $100 \mathrm{~mm}$ were recorded in the crops in October (flowering), November and December (graining), February and March (maturation). In the 2017/2018 harvest, rainfall greater than $100 \mathrm{~mm}$ occurred in October, December and January (graining); February, March and April (maturation); and May (rest). In both harvests, climatic conditions in the region were favorable to coffee production to some extent.

According to the methodology described by Santos et al. (2018), the soil in the region is classified as Cambisol, with characteristic clayey-sandy texture, containing $0.46 \mathrm{~kg} \mathrm{~kg}^{-1}$ clay, $0.09 \mathrm{~kg} \mathrm{~kg}^{-1}$ silt, and $0.45 \mathrm{~kg} \mathrm{~kg}^{-1}$ total sand, on average.

The crops were fertilized according to the results from the chemical analysis of the soil and leaf tissues, right after finishing the harvesting of the previous crop. Macronutrient fertilization was hauled at the plant canopy, applied in three stages, every 90 days. Micronutrients together with pesticides were applied using a backpack sprayer divided into three preventive applications, one insecticide and two fungicides in November, March, and July.

The two crops were cultivated in the $1.50 \times 1.50 \mathrm{~m}$ spacing, and the farmer prepared the seminal (S) seedlings. In the clonal crop (C), thirteen clones of the Vitória INCAPER 8142 variety were cultivated, according to the classification of the fruit maturation stages, being: five early, six intermediate and two late clones, which were distributed in the crop following the technical recommendation.

Prior to NPK fertilization, the farmer controls the weeds in between rows with motorized hand mowers every 90 days. An herbicide is applied twice a year, before (May) and after (September) harvesting, during the pruning period.

When $80 \%$ of coffee fruits reached the cherry stage, harvesting was performed manually in sieves for the two genotypes studied. The seminal variety (S) was harvested in the first half of June/2017 and 2018 whereas the clonal varieties (C) were harvested between May and July/2017 and 2018, according to the three stages of fruit maturation.

The ripe fruits harvested from the two genotypes $(\mathrm{S}, \mathrm{C})$ were divided into fruits with skin (natural - N) and mechanically peeled $(\mathrm{P})$ and were immediately placed on concrete floor in greenhouse for drying. The maturation stages of the clonal varieties (C) were considered in the drying of the fruits.

The fruits were dried to $\pm 12 \%(\mathrm{wb})$, monitored with a grain moisture meter. Subsequently, the fruits were mechanically peeled $(\mathrm{P})$ to remove the skin and parchment for the natural process $(\mathrm{N})$ while the parchment was removed from the coffee beans that were mechanically peeled $(\mathrm{P})$ before drying.

The hulled beans were classified in round sieve screens for flat grains, as described by Loures, Alves and Aloise Junior (2007). In the 2016/2017 crop, a set of four sieves with openings of 13 and 14 (flat grain) and 15 and 16 (medium flat grain) (64 inches) were arranged to overlap and fitted in descending order (16, 15, 14 and 13). In the 2017/2018 harvest, the sieve 17 (coarse flat grain) was also used. The process of coffee grading is done by passing unroasted beans through the set of sieves, starting with the largest diameter screen, that is moved continuously/intermittently during $15 \mathrm{~s}$. So that, Class 16 sieves retain grains larger than 16/64" diameter holes while Class 15 sieves retain those larger than the 15/64" diameter holes, and so on.

After grading, up to $0.50 \mathrm{~kg}$ of coffee bean samples were stored in paper bags, totaling four samples per sieve. The 2016/2017 crop samples were stored in a sealed Styrofoam box for 45 days, as described by Silva et al. (2016) and Lima and Silva (2018). The 2017/2018 crop samples were stored in the same hermetically sealed packaging for 90 days. After the storage periods, the coffee samples were sent for physical and sensory analyses.

From each treatment, $0.30 \mathrm{~kg}$ samples of coffee beans were separated and used to determine the number of defective coffee beans per sample. The quantification of defects followed the Normative Instruction No. 8 (2003) of the Ministry of Agriculture, Livestock and Supply (MAPA), which characterizes and quantifies the defects of coffee bean samples.

The sensory analyses to determine the quality of the beverages produced from the different treatments consisted of coffee cupping that was performed by a team of three specialized tasters, known as "R-Graders", certified by the Coffee Quality Institute (CQI). The beverages were tasted and scored according to the two genotypes (seminal- $\mathrm{S}$ and clonalC), processing methods (natural-N and peeled-P), coffee classification in sieves and storage periods. Thus, the coffee samples for the sensory analyses were prepared and blindly evaluated following the methodology of the C. canephora coffee tasting protocol (ICO, 2010), as mentioned by Lima and Silva (2018) and Souza et al. (2018).

In this study, the final overall score (OS) was based on the following variables fragrance (aroma), flavor, bitterness (sweetness), overall taste, balance, cleanliness, aftertaste, 
sensation, uniformity and salinity (acidity), according to protocol.

The experiments followed a completely randomized design (IHD), a factorial scheme, 2 (genotypes) x 2 (processes) x 4 (sieves) x 4 (repetitions) in the 2016/2017 harvest and 2 (genotypes) $\times 2$ (processes) $\times 5$ (sieves) $\times 3$ (repetitions) in the $2017 / 2018$ harvest, and the overall score (OS) as a dependent variable. The significant sources of variation in the analysis of variance (ANOVA) $(\mathrm{p}<0.05)$ were analyzed by Tukey test. The t-test $(p<0.05)$ was used to verify the significance between the OS averages for the same treatment between the two harvests.

\section{RESULTS AND DISCUSSION}

The average overall scores (OS) assigned to the beverage brewed using the Conilon coffee beans from the 2016/2017 and 2017/2018 harvests, after the sensory analysis, are shown in Figures 1 and 2, respectively.

Figure 1 shows that after a 45-day storage, the average OS (in parenthesis) between 80 and 85 points were assigned to the following samples: PC16 (84.3) (mechanically peeled clonal coffee cherry, sieves 16), PS16 (81) (peeled seminal coffee cherry, sieve 16), and PC15 (81.7) (peeled clonal coffee cherry, sieve 15).

\section{$2016 / 2017$ harvest}

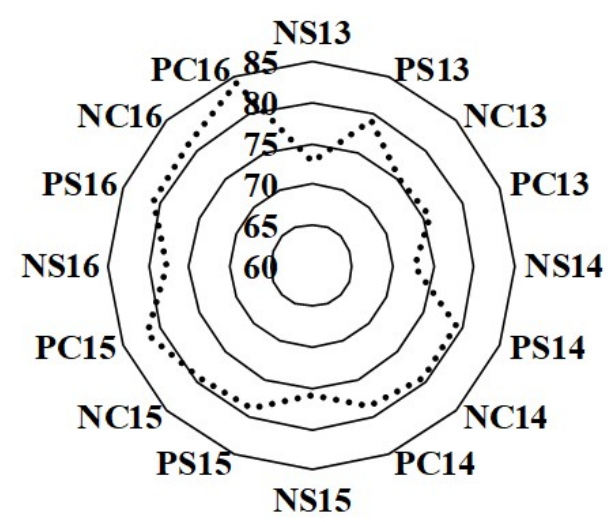

Figure 1: Radar chart of the overall scoring for the beverage prepared from Conilon coffee beans after 45-day storage (2016/2017 harvest).

Average overall scores between 75 to 80 points were assigned to the samples NS16 (77.8) (natural seminal, sieves 16), PS15 (78.9), NS15 (75.8), PC14 (78.7), PS14 (79.2), PC13 (75.7), NC13 (75.1), and PS13 (79.3). Furthermore, overall scores below 75 points were assigned to the natural seminal samples, sieves 13 (NS13) (72.8) and 14 (NS14) (72.8). Likewise, Lima and Silva (2018) investigated the quality of the beverage obtained from the clonal conilon coffee beans in this same area and reported an 85-point OS for depulped beans from two clones in the intermediate-maturity stage. These authors cite that the grades of conilon coffee beverage between 70 to 80 and 80 to 90 points are classified as very good coffee and fine coffee, respectively, following the CQI protocol (Coffee Quality Institute - CQI, 2011).

Figure 2 shows the average overall scores assigned to the beverage prepared from the coffee beans of the $2017 / 2018$ harvest, after 90 days of storage. It is observed that no treatment had an overall score greater than 80 points. Furthermore, overall scores between 75 and 80 points were obtained for NS16 (77.6), NS17 (76.0), NC13 (76.7), NC14 (78.3), NC15 (78.8), NC16 (78.3), NC17 (77.8), PC13 (77.0), PC14 (77.4), PC15 (77.0) and PC17 (76.3). Overall scores between 70 to 75 points were obtained for SNS15 and PC16 whereas between 70 to 60 points were assigned to NS13 (67.8), NS14 (67.5), PS13 (67.5), PS14 (60.0), PS15 (60.0), PS16 (69.8), and PS17 (68.6).

\section{$2017 / 2018$ harvest}

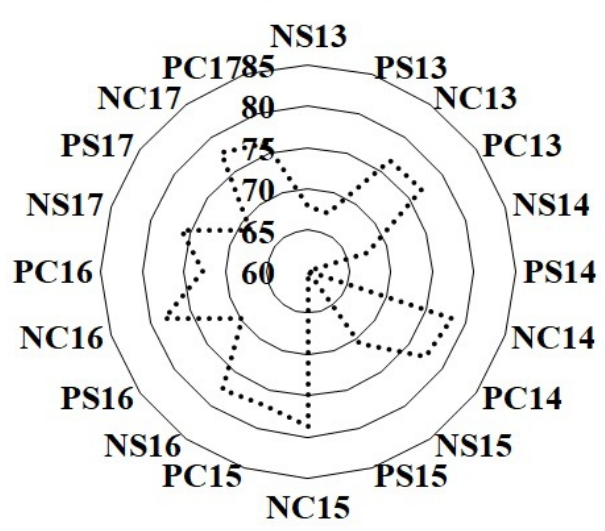

Figure 2: Radar chart of the overall scoring for the beverage prepared from Conilon coffee beans after 90-day storage (2017/2018 harvest).

The results of the coffee cupping seem to indicate that although not identified, the 90-day storage period caused the appearance of fungi in the coffee beans since the quality of the beverage was somewhat altered during the sensory analysis.

At least one sample scored 60 points, an overall score below 70 points is characteristic of beverage prepared using moldy coffee beans (chemical fermentation). All coffee samples prepared with mechanically peeled seminal coffee beans in the sieves 14 and 15 (PS14 and PS15) scored 60 points in the sensory analysis, which seems to indicate that the coffee beans lost quality during the storage period in the 2017/2018 harvest. According to Bokhari (2007), coffee beans are prone to contamination by microorganisms during fruit development, after harvest, and during storage. This author also claims that microorganisms such as bacteria, yeast, and filamentous fungi interfere with the quality of the beverage. 
Bozza et al. (2009) showed that arabica coffee fruits harvested in the plant and collected in the soil were contaminated with different genera of fungi and concluded that the quality of the beverage is affected by mycotoxins that cause harmful biological changes. Rendón, Salva, Bragagnolo (2013) showed that coffee beans are conventionally processed and stored in places without any control of temperature and humidity, favoring the appearance of fungi leading to losses in sensory quality.

The analysis of variance (ANOVA) of the overall scores obtained in the 2016/2017 harvest showed a Genotype $\mathrm{x}$ Process $\mathrm{x}$ Sieve interaction with significant difference in at least two average overall scores.

Table 1 shows the results of a significant Genotype $\mathrm{x}$ Process $\mathrm{x}$ Sieve interaction. It is verified that OS for the seminal coffee beans (S) is significantly higher for peeled beans (P) compared to those dried with skin (natural-N). Furthermore, the overall scores of the beverages prepared with clonal coffee $(\mathrm{C})$ beans Sieves 15 and 16 were significantly higher for mechanically peeled (P) beans compared to those with the skin, natural $(\mathrm{N})$.

The OS of the beverage prepared from mechanically peeled clonal (PC) and natural seminal (NS) coffee beans increased with increasing grain size (higher-grade coffees).

Ribeiro et al. (2014) and Souza et al. (2018) select the overall average score (OS) of 68.4 and 66.5, respectively, for clonal conilon coffee, classified as good quality coffee and not specific for the type of sieve in the studies. Fonseca et al. (2019) found OS of 75.4 for seminal conilon coffee produced at high altitude, classified as very good coffee, separated in sieves 13 .

The OS of the beverage prepared from the natural clonal (NC) coffee beans is higher for sieve 16 compared to sieves 13, 14 and 15. However, the OS of the beverage prepared with mechanically peeled clonal (PC) coffee beans increases significantly with increasing grain size.

The beverage prepared with natural (NS) and mechanically peeled (PS) seminal coffee beans presented the highest overall scores for sieves 15 and 16, and sieve 16, respectively.

According to the tasters, no samples of moldy coffee beans (chemical fermentation) were identified after 45 days of grain storage. According to Batista et al. (2003), the presence of fungi, besides the risks of contaminating the beans with mycotoxins, can alter the product quality and the chemical composition of the coffee.

The results for the 2017/2018 harvest shown in Table 2 indicate a significant genotype $\mathrm{x}$ sieve interaction. Clonal (C) and seminal (S) coffee bean samples have significantly different overall scores of 77.0 and 68.6 , respectively, according to the F test results $(\mathrm{p}<0.05)$.

The OS for clonal coffee beans (C) was not significantly different between sivies. However, the OS of the beverage obtained from the clonal (C) compared to seminal (S) coffee beans is significantly different for sieves 13,14 and 15 whereas both seminal (S) and clonal (C) coffee beans sieves 16 and 17 produce coffee with an overall score not significantly different. It is noteworthy that a sample of sieve 17 mechanically peeled seminal (PS) got an overall grade 60, decreasing the average overall score.

Studies have shown that coffee beans stored for 12 months in hermetic packaging on a commercial scale, under conditions of modified and controlled atmospheres, as described by Ribeiro et al. (2011), contributes to preserve the sensory quality of the beverage of arabica coffee beans

The overall scores (OS) were significantly different between the two harvests for the studied treatments, according to t-test ( $p<0.05$ ). The treatments PS13, PS14, PS15, PS16, PC15, and PC16 were significantly different, indicating that the OS decreased during the 90-day sample storage in the 2017/2018 harvest (Table 3). However, the OS for the other treatments were not significantly different between the two harvests.

Abreu et al. (2017) used techniques to simulate the time and the appropriate temperature for the storage beans of Coffea arabica, mechanically peeled after drying with skin, and concluded that the storage time was 90 days and at a temperature of $10^{\circ} \mathrm{C}$, indicating that this conditions is suitable for beans quality and sensory analysis.

Partelli et al. (2014) studied the quality of the beverage obtained from dry Coffea Canephora on the concrete floor in greenhouse. The samples were peeled when $22 \%, 19 \%$ and $16 \%(\mathrm{wb})$ moisture. The peeled samples were returned to the greenhouse until they reached the desired moisture level of

Table 1: Tukey test results for genotypes, processes (natural and mechanically peeled) and sieves $(13,14,15$ and 16$)$ interaction, after 45-day storage (2016/2017 harvest).

\begin{tabular}{ccccccccccc}
\hline \multicolumn{10}{c}{ Genotypes - Sieves } \\
\hline Process & $\mathrm{S} 13$ & $\mathrm{~S} 14$ & $\mathrm{~S} 15$ & $\mathrm{~S} 16$ & $\mathrm{C} 13$ & $\mathrm{C} 14$ & $\mathrm{C} 15$ & $\mathrm{C} 16$ & Average \\
\hline $\mathrm{N}$ & $72.8 \mathrm{Bb}$ & $72.8 \mathrm{Bb}$ & $75.8 \mathrm{Ba}$ & $77.8 \mathrm{Ba}$ & $75.1 \mathrm{Ac}$ & $79.5 \mathrm{Ab}$ & $79.4 \mathrm{Bb}$ & $81.2 \mathrm{Ba}$ & $76.8 \mathrm{~B}$ \\
$\mathrm{P}$ & $79.3 \mathrm{Ab}$ & $79.2 \mathrm{Ab}$ & $78.9 \mathrm{Ab}$ & $81.0 \mathrm{Aa}$ & $75.7 \mathrm{Ad}$ & $78.7 \mathrm{Ac}$ & $81.7 \mathrm{Ab}$ & $84.3 \mathrm{Aa}$ & $79.9 \mathrm{~A}$ \\
\hline
\end{tabular}

$\mathrm{S}$ : seminal coffee; C: clonal coffee; $\mathrm{N}$ : natural, fruit with skin; P: mechanically peeled coffee beans.

Means followed by the same uppercase letter in the column do not differ significantly by Tukey $(p<0.05)$.

Means followed by the same lowercase letter in the row do not differ significantly by Tukey $(p<0.05)$. 
$13 \%(\mathrm{wb})$. They concluded that the early peeling of conilon coffee did not affect the final quality of the beverage.

Table 2: Tukey test results of genotype and sieve interaction (2017/2018 harvest) (90 days storage).

\begin{tabular}{ccccccc}
\hline \multicolumn{7}{c}{ Sieves } \\
\hline Genotypes & 13 & 14 & 15 & 16 & 17 & Average \\
\hline $\mathrm{S}$ & $67.7 \mathrm{Bab}$ & $63.8 \mathrm{Bb}$ & $65.4 \mathrm{Bb}$ & $73.7 \mathrm{Aa}$ & $72.3 \mathrm{Aab}$ & $68.6 \mathrm{~B}$ \\
$\mathrm{C}$ & $76.9 \mathrm{Aa}$ & $77.9 \mathrm{Aa}$ & $77.9 \mathrm{Aa}$ & $75.5 \mathrm{Aa}$ & $77.1 \mathrm{Aa}$ & $77.0 \mathrm{~A}$
\end{tabular}

S: seminal coffee; C: clonal coffee.

Means followed by the same lowercase letter in the row do not differ significantly by Tukey $(p<0.05)$.

Means followed by the same uppercase letter in the column do not differ significantly by $\mathrm{F}$ test $(\mathrm{p}<0.05)$.

Table 3: Average general score (OS) for coffee beans from different sieves in the two harvests, according to t-test $(p<0.05)$.

\begin{tabular}{ccccccc}
\hline Harvests & PS13 & PS14 & PS15 & PS16 & PC15 & PC16 \\
\hline 2016/2017 & $79.3 \mathrm{~A}$ & $79.2 \mathrm{~A}$ & $78.9 \mathrm{~A}$ & $81.0 \mathrm{~A}$ & $81.7 \mathrm{~A}$ & $84.3 \mathrm{~A}$ \\
2017/2018 & $67.5 \mathrm{~B}$ & $60.0 \mathrm{~B}$ & $60.0 \mathrm{~B}$ & $69.8 \mathrm{~B}$ & $77.0 \mathrm{~B}$ & $72.7 \mathrm{~B}$ \\
\hline
\end{tabular}

S: Seminal coffee; C: Clonal coffee; P: mechanically peeled coffee beans.

Means followed by the same uppercase letter in the column do not differ by t-test $(p<0.05)$.

Furthermore, the objective of this research was not to identify the fungi present in coffee samples during the bean storage periods. According to Pasin, Almeida e Abreu (2009), the occurrence of certain toxins depends on intrinsic and extrinsic factors to the beans that may inhibit or potentiate the effect of mycotoxins.

During the drying process on the concrete floor in greenhouse of the mechanically peeled fruits $(\mathrm{P})$, it may have somehow facilitated the contamination of the beans, because they are still involved in the mucilage. During the storage time, these mycotoxins manifested significantly, causing a significant drop in the final quality of the beverage. Perrone et al. (2007) stated that the diversity of fungi found in coffee beans depends on several factors, such as variety, producing region, climate and fruit processing method after harvest. According to Souza et al. (2018), the genetic component was more important than the environmental in the expression of quality attributes of conilon coffee.

\section{CONCLUSIONS}

During the 45 day storage period, the seminal coffee beans (S) dried mechanically peeled (P) present higher overall score (OS) on the quality of the beverage when compared to dry with skin $(\mathrm{N})$ in all sieves and coffee beans (C) only in sieves 15 and 16. In the 90 days storage period, the fruits hulling does not influence the quality of the beverage, the clonal coffee beans (C) in the sieves 16 and 17 has a higher overall score (OS) compared to the seminal (S). The increase in storage time from 45 to 90 days caused loss of quality of the beverage due to the occurrence of fungi in the beans.

\section{ACKNOWLEDGMENTS}

To CNPq for the financial support to this research.

\section{REFERENCE}

ABREU, G. F. et al. Simultaneous optimization of coffee quality variables during storage. Revista Brasileira de Engenharia Agrícola e Ambiental, 21(1):56-60, 2017.

BATISTA, L. R. et al. Toxigenic fungi associated with processed (green) coffee beans (Coffea arabica L.) International Journal of Food Microbiology, 85:293300, 2003.

BOKHARI, F. M. Mycotoins and toxigenic fungi arabic coffee beans in Saudi Arabic. Advances in Biological Research, 1(1/2):56-66, 2007.

BOZZA, A. et al. Isolamento de fungos associados a grãos de café Iapar 59 de origem de solo e árvore em diferentes tempos de colheita. Ciência e Tecnologia de Alimentos, 29(3):529-534, 2009.

\section{COFFEE QUALITY INSTITUTE - CQI. Fine Robusta} Coffee Standards and Protocols. 2011. Available in: $<$ http://www.coffeeinstitute.org/>. Access in: 07 Sep. 2017.

FONSECA, A. S. et al. Fuzzy logic in the spatial and temporal distribution in the quality the beverage in conilon coffee. Coffee Science, 14(2):163-172, 2019.

ICO - Internacional Coffee Organization - Robusta cupping protocols. Available in: <http://www.ico.org/documents/ pscb-123-e-robusta.pdf>. Access in: 18 Aug. 2017.

KÖPPEN, W.; GEIGER, R. Klimate der Erde. Gotha: Verlag Justus Perthes. 1928.

LIMA, J. S. S.; SILVA, S. A. Fuzzy application and cluster analysis in the quality of the beverage from Conilon Coffee. Coffee Science, 13(4):439-447, 2018.

LOURES, C. R.; ALVES, O. A. A. R.; ALOISE JUNIOR, R. Classificação e degustação do café (Coffea arabica). Ed. LK. 2007. 119p.

PARTELLI, F. L. et al. Quality of conilon coffee dried on a concrete terrace in a greenhouse with early hulling. Semina: Ciências Agrárias, 35(5):2367-2372, 2014. 
PASIN, L. A. A.; ALMEIDA, J. R.; ABREU, M. S. Fungos associados a grãos de cinco cultivares de café (Coffea arabica L.). Acta Botânica Brasilica, 23(4):1129-1132, 2009.

PERRONE, G. et al. Biodiversity of Aspergillus species em some importante agricultural products. Studies in Micology, 59:53-66, 2007.

PIMENTA, C. J.; VILELA, E. R. Composição microbiana e Ochratoxin A no café (Coffea arabica L.) submetidos a diferentes tempos de espera antes da secagem. Ciência e Agrotecnologia, 27(6):1315-1320, 2003.

RENDÓN, M. Y.; SALVA, T. J. G.; BRAGAGNOLO, N. Impact of chemical changes on the sensory characteristics of coffee beans during storage. Food Chemistry, 147:279-286, 2013.

RIBEIRO, B. B. et al. Avaliação química e sensorial de blends de Coffea canephora e Coffea arabica L. Coffee Science, 9(2):178-186, 2014.

RIBEIRO, F. C. et al. Storage of green coffee in hermetic packaging injected with $\mathrm{CO}_{2}$. Journal of Stored Products Research, 47:341-348, 2011.
SANTOS, H. G. et al. Sistema Brasileiro de classificação de solos. 5a Edição. Brasília - DF, EMBRAPA, 2018. $356 \mathrm{p}$.

SILVA, S. A. et al. Fungi associated to beans infested with coffee berry borer and the risk of ochratoxin A, Food Control, 113:1-7, 2020.

SILVA, S. A. et al. Mapping the potential beverage quality of coffee produced in Zona da Mata, Minas Gerais, Brazil. Journal of Science of Food and Agriculture, 9(9):30983108, 2016.

SOUZA, C. A. et al. Characterization of beverage quality in Coffea canephora Pierre ex A. Froehner. Coffee Science, 13(2):210-218, 2018.

TAVEIRA, J. H. S. et al. Post-harvest effects on beverage quality and physiological performance of coffee beans. African Journal of Agricultural Research, 10(12):14571466, 2015.

VERDIN FILHO, A. C. et al. Research The beverage quality of Conilon coffee that is kept in the field after harvesting: Quantifying daily losses. African Journal of Agricultural, 11(33):3134-3140, 2016. 